\title{
Horizontal Resolution Needs for Adequate Lower Tropospheric Profiling Involved with Atmospheric Systems Forced by Horizontal Gradients in Surface Heating
}

\author{
R. A. PIELKF \\ Department of Atmospheric Science, Colorado State University, Fort Collins, Colorado \\ G. KALLOS \\ Department of Applied Physics, University of Athens, Athens, Greece \\ M. SEGAL \\ Department of Atmospheric Science, Colorado State University, Fort Collins, Colorado
}

(Manuscript received 30 May 1988, in final form 22 March 1989)

\begin{abstract}
For a propagating mesoscale system whose intensity and structure is not changing with time, relatively coarse horizontal profiler resolution is sufficient to resolve the feature since the circulation would pass by the profiler sites quickly enough to construct a three-dimensional analysis. This is generally not true for a thermally forced mesoscale system. For mesoscale systems generated by surface inhomogeneities in surface heating (e.g., landsea contrasts, nonuniform soil wetness, etc.), such propagation is often slow. Therefore, ideally, if thermally surface-forced systems are to be directly resolved by a profiler network, a necessary condition is that their spacing be close enough to adequately resolve the motion field of the mesoscale system. As concluded from the analyses in this paper, higher spatial resolution is required to directly monitor the horizontal wind field than the temperature field, since the horizontal wind is proportional to the horizontal gradient of temperature. Similarly, even higher resolution of vertical velocity is required since ascent and descent are proportional to the horizontal gradient of the horizontal velocity.

The use of mesoscale numerical models as analysis tools, however, offers the opportunity to obtain fine-scale horizontal resolution with only relatively coarse atmospheric data. Such fine scale resolution is obtained because the surface thermal forcing can be resolved with high spatial accuracy and, through nonlinear advection and the pressure gradient force in the numerical model, fine-scale atmospheric structure can be produced.

Finally, stringent data initialization requirements would result if one attempted to insert mesoscale resolution profiler-derived temperature or wind data into a model. Even if $10-\mathrm{km}$ horizontal resolution were obtained with a profiler network and if relative errors in the temperature measurements were only $0.24^{\circ} \mathrm{C}$ through a depth of $2 \mathrm{~km}$ or so, a fictitious $1 \mathrm{~m} \mathrm{~s}^{-1} \mathrm{~h}^{-1}$ acceleration would result. For the same resolution, for winds from one profiler of 0,5 , and $10 \mathrm{~m} \mathrm{~s}^{-1}$, an error from the adjacent profiler of $2.4,0.5$, and $0.3 \mathrm{~m} \mathrm{~s}^{-1}$, respectively, would result in the same erroneous acceleration.
\end{abstract}

\section{Introduction}

The addition of an observational technique to assess the wind structure of the lower troposphere at frequent intervals offers an opportunity to improve mesoscale analysis as well as the initialization and the validation of mesoscale ${ }^{1}$ models. An effective tool to evaluate

Corresponding author address: Dr. Roger A Pielke, Dept. of Atmospheric Science, Colorado State University, Fort Collins, CO 80523.

\footnotetext{
${ }^{1}$ Mesoscale is defined in this paper to refer to atmospheric features that are hydrostatic, but whose horizontal winds deviate significantly from gradient wind balance even above the planetary boundary layer. Since the mesoscale is hydrostatic, knowledge of the temperature field and its time evolution are sufficient to specify the total wind field. The horizontal scale involved is up to several hundred kilometers.
}

strategies involved with optimal implementation of such measurement networks is to use a numerical model. Such an approach was applied, for example, by Kuo et al. (1987) while considering synoptic scale systems. Significant weather phenomena are related to mesoscale thermally induced circulations. In the United States, for example, sea breeze related summer cloud convection in Florida, the Great Lakes, and southern Texas and summer daytime formation of convective clouds triggered by upslope circulations along the Rocky Mountains are a common feature (Pielke 1984).

Recently, it was suggested (e.g., Segal et al. 1984; Pielke and Segal 1986) that a nonuniform surface sensible heat flux distribution within mesoscale domains is a frequent occurrence in the real world and should provide a forcing of mesoscale circulations (termed Non-Classical Mesoscale Circulations- 
NCMCs ). Typical situations involved with NCMCs may be related to horizontal soil wetness gradients, dry land-vegetation contrasts, cloud area-clear area contrasts, and snow-bare soil contrasts. Even if the intensity of NCMCs is relatively weak, the related horizontal gradients of the convective boundary layer depth and of the available convective buoyant energy are likely to modify the large scale flow locally.

The importance of mesoscale circulations in weather forecasting, as well as in other applied environmental studies, suggest that attention be given to the ability to resolve these features by a profiler network. The present paper presents preliminary evaluations relating to the horizontal profiler network resolution needed to effectively resolve two types of common thermally forced mesoscale systems-the sea breeze (sections 2 and 4 ) and upslope flow (section 3 ), while providing a qualitative general evaluation of their characteristics ( section 5). The potential impact of nonuniform surface thermal forcing within a mesoscale domain on wind, temperature, and moisture fields is outlined in section 6. General scaling evaluations as related to possible errors due to insufficient horizontal profiler resolution are given in section 7 .

\section{Sea breeze analysis}

In order to investigate what spatial and temporal resolution of sea breezes result from different spacings of profilers, an illustrative control sea breeze numerical simulation was performed. The formulation of the model used is given in Pielke (1974) and Mahrer and Pielke (1977). In the current simulations, it consists of 20 levels with a top at $13 \mathrm{~km}$. The soil physical constants are as in Mahrer and Pielke (1977), while the initial atmospheric potential temperature lapse is $3.5 \mathrm{~K} \mathrm{~km}^{-1}$. The horizontal grid interval is $6 \mathrm{~km}$; with this grid resolution, atmospheric features larger than four grid intervals are reasonably well resolved. The domain size was $540 \mathrm{~km}$ where $240 \mathrm{~km}$ consisted of land and $300 \mathrm{~km}$ of water. An offshore geostrophic flow of $1.5 \mathrm{~m} \mathrm{~s}^{-1}$ was applied in order to permit the development of a well-defined, opposing sea breeze. The simulations commenced at 0600 LST using solar radiation conditions for 14 August at a latitude of $32^{\circ} \mathrm{N}$ and an initial surface temperature of $25^{\circ} \mathrm{C}$.

Selected model $x-z$ fields are presented in Fig. 1 at around the time of maximum sea breeze development (1400 LST). Of particular interest for the current paper is the tight horizontal potential temperature gradient in Fig. 1a, which results, through the horizontal pressure gradient force, in the horizontal and the vertical velocity fields shown in Figs. $1 \mathrm{~b}$ and $1 \mathrm{c}$, respectively. Figure 1d illustrates the venting of moisture higher into the lower troposphere as a result of the sea breeze convergence evident in Fig. 1c.

To be effective at monitoring this sea breeze by means of a profiler network, generally it must have spacing such that (i) at the very least, the magnitudes of $u, \theta$ and $q$ are reasonably resolved over the land area and at several levels in the lower troposphere; and (ii) desirably, the horizontal gradients of $u, \theta$, and $q$, are also adequately measured. The next set of experiments is designed to provide an evaluation of these requirements.

Assuming that the simulation results presented above represent a real-world sea breeze, termed the control simulation in this paper, then for this situation, if the profilers are set at horizontal intervals of $6 \mathrm{~km}$ corresponding to the model grid points, their observations will provide an identical analysis as obtained in the control simulation (provided, of course, the vertical resolution of the profilers is equivalent to that of the numerical model). When the profilers are sited with coarser horizontal resolution, however, the interpolated fields obtained through contour analysis will obviously depart from the original resolved fields (i.e., in the control simulation). In order to examine the differences, a contour analysis was carried out based on availability of data every 5 grid points, 10 grid points, and 15 grid points [i.e., reflecting a horizontal profiler separation of $30 \mathrm{~km}$ (with 19 profilers), $60 \mathrm{~km}$ (with 10 profilers), and $90 \mathrm{~km}$ ( 7 profilers), respectively].

Figure 2 presents the results obtained with a separation of $90 \mathrm{~km}$. The smearing of the gradients of $\theta$ and $q$ become increasingly more serious as the resolution of analysis degrades. The resolved maximum of $u$ is reduced from over $7 \mathrm{~m} \mathrm{~s}^{-1}$ in the control to about $4 \mathrm{~m} \mathrm{~s}^{-1}$ in the $90 \mathrm{~km}$ resolution analysis. The maximum vertical velocity, $w$, reduces from $30 \mathrm{~cm} \mathrm{~s}^{-1}$ to about $3 \mathrm{~cm} \mathrm{~s}^{-1}$. It should be noted that the values of $w$ were adopted from the control simulation $w$ field at the profiler locations. Computing the $w$ profiles based on the profilers' $u$ values (assuming a 2-D case), would result in even lower absolute values of $w$ in most cases. This large change results mostly because the horizontal sea breeze convergence is narrow and is missed almost completely by the selected $90-\mathrm{km}$ resolution spacing.

Figure 3 repeats the analysis except that the data points used in the analysis (i.e., the "profiler network") are shifted by one-half the resolution spacing in Fig. 2 (Fig. 3 analyses data points are shifted $45 \mathrm{~km}$, relative to Fig. 2). Comparing Figs. $2 b$ and $3 b$, for example, the horizontal velocity peak has changed from around $4 \mathrm{~m} \mathrm{~s}^{-1}$ to over $7 \mathrm{~m} \mathrm{~s}^{-1}$. The latter value is close to the maximum in the control analysis (Fig. 1b) since the peak value was fortuitously included in the analysis shown in Fig. 3b, although the remainder of the patterning is poorly resolved.

Since the profilers would be fixed in space while the sea breeze convergence zone would propagate across the region, it would be useful to evaluate how the maximum and minimum values of the analyzed variables change as a function of time. A "profiler network" with 

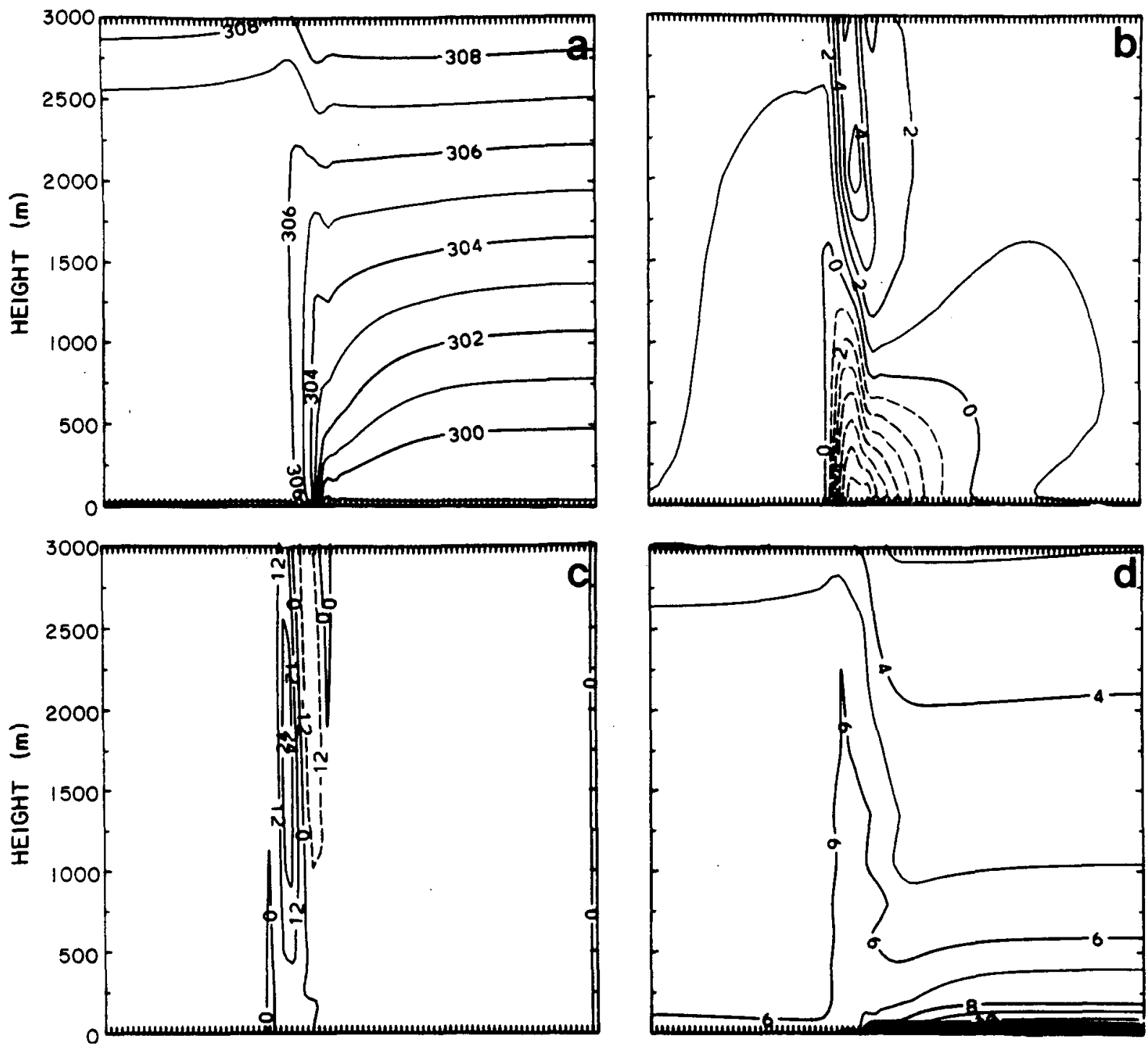

FIG. 1. Simulated sea breeze fields in a vertical cross section at 1400 LST for the control case: (a) potential temperature, $\theta$, (K) (b) cross-shore wind velocity component, $u,\left(\mathrm{~m} \mathrm{~s}^{-1}\right),(\mathrm{c})$ vertical velocity, $w,\left(\mathrm{~cm} \mathrm{~s}^{-1}\right)$, (d) specific humidity, $q,\left(\mathrm{~g} \mathrm{~kg}^{-1}\right)$. The sea segment is indicated by the dark line.

separations of 30,60 and $90 \mathrm{~km}$ were considered as well as a shifting of their location by one-half of their separation distance (i.e., 15,30 and $45 \mathrm{~km}$ respectively). Figure 4 illustrates the maximum and minimum values of $u$ and $w$ in the lowest $3 \mathrm{~km}$ of the domain, whereas Fig. 5 illustrates the maximum and minimum values of $\theta$ and $q$ at the first model levela height of $5 \mathrm{~m}$ (denoted $u_{\max }, u_{\min } ; w_{\max }, w_{\min } ; \theta_{\max }$, $\theta_{\min }$, and $q_{\max }, q_{\min }$, respectively). ${ }^{2}$ The control analysis is graphed using open circles.

\footnotetext{
${ }^{2}$ With current and anticipated microwave profiling capabilities, $\theta$ and $q$ at 5 meters are unobtainable using this technology. Other types of profilers (e.g., lidars), however, would be capable of this resolution.
}

Conclusions which can be extracted from these graphed features are:

(i) The values of $u_{\max }$ are almost always underestimated when the horizontal resolution is degraded. The magnitude of the $u_{\min }$ is also almost always underestimated.

(ii) The values of $w_{\min }$ becomes very irregular with time as the spatial resolution is degraded. Such irregularity occurs because of the small horizontal extent of the upward motion cell of the sea breeze. This small horizontal extent is resolved very poorly by the profilers, as the convergence zone propagates inland. The values of $w_{\min }$, although almost always underestimated, 

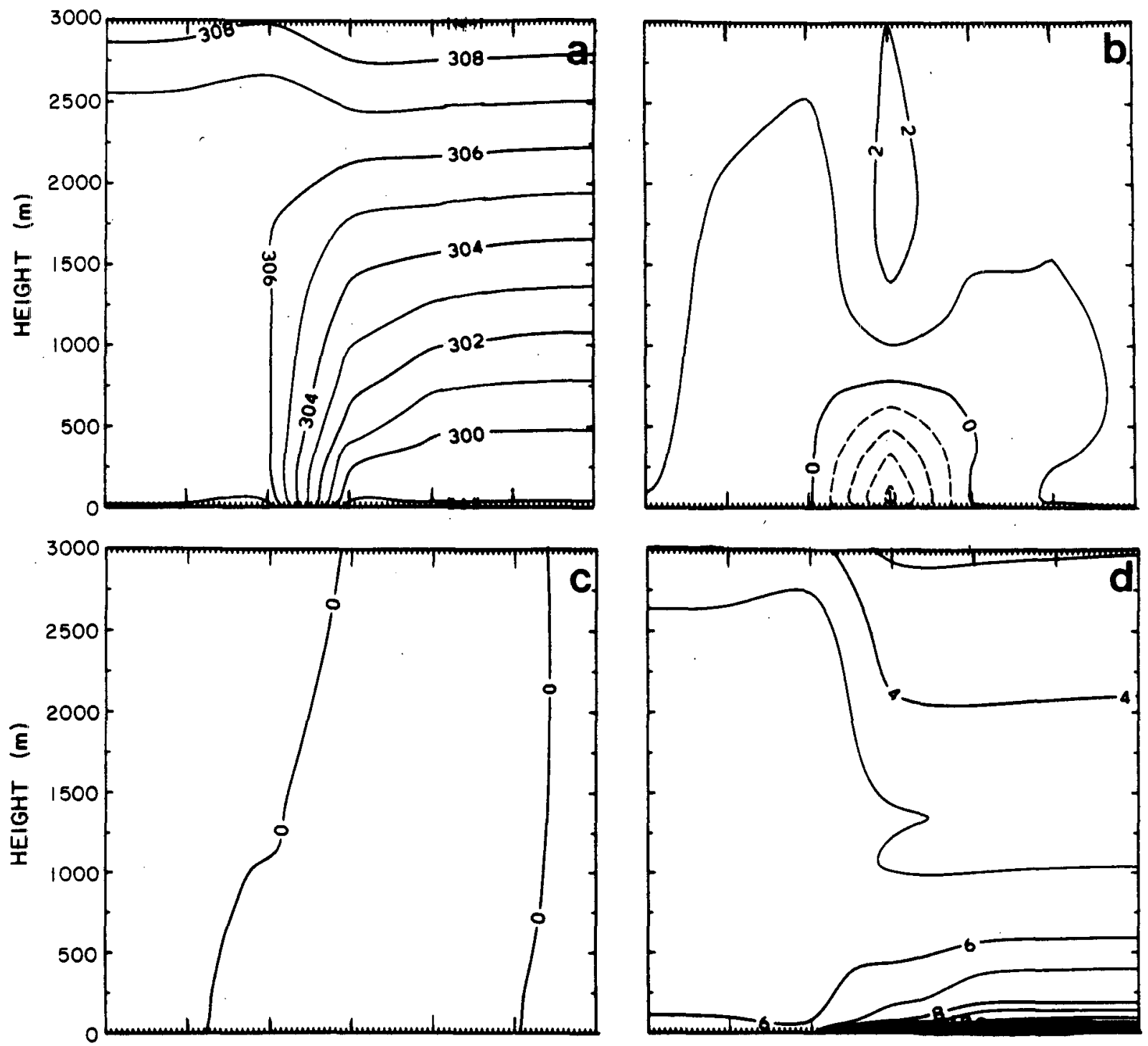

FIG. 2. Interpolation of the fields described in Fig. 1 using the simulated vertical profiles every $90 \mathrm{~km}$ (at points marked by the taller tic marks) as a database.

is less irregular because the subsiding branch of the sea breeze covers a larger horizontal extent.

(iii) The near-surface $\theta_{\max }$ and $\theta_{\min }$ as well as near the surface $q_{\max }$ and $q_{\min }$ values are much better resolved even for the coarsest horizontal resolution analyzed. This degree of agreement results because $\theta$ and $q$ are most directly related to the surface heat and moisture forcing which is inserted into this model simulation over a horizontal scale of almost $250 \mathrm{~km}$. The horizontal velocity, in contrast, develops in response to the horizontal gradient of $\theta$, which has a much smaller horizontal scale of around $30 \mathrm{~km}$. The spatial scale of the horizontal velocity maxima and minima are, therefore, much smaller. Finally, vertical velocity develops from horizontal gradients of $u$, which produces an even smaller horizontal scale for $w$.

\section{Slope flow analysis}

The next set of experiments is analogous to that presented in the last section except a thermally forced upslope flow is simulated. The initial conditions in the present case are identical to the conditions prescribed for the sea breeze simulation. The grid interval and domain are again $6 \mathrm{~km}$ and $540 \mathrm{~km}$, respectively. The terrain consists of a plain with MSL elevation along a distance of $216 \mathrm{~km}$, a linear slope reaching the height of $1200 \mathrm{~m}$ after a distance of $180 \mathrm{~km}$, and an elevated 

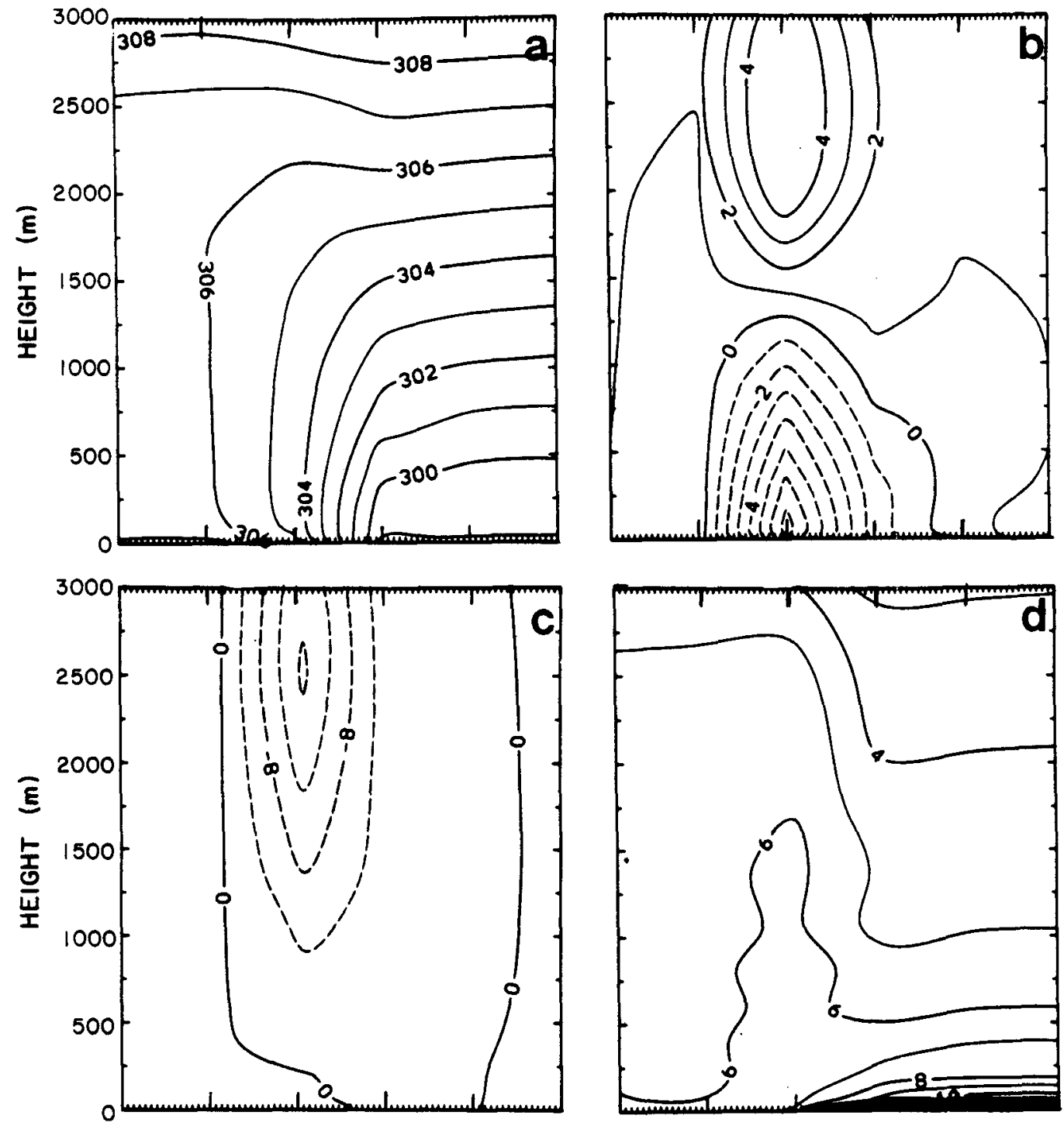

FIG. 3. The same as Fig. 2 except for shifting the location of the vertical profiles used in Fig. 2 by $45 \mathrm{~km}$.

plateau for $144 \mathrm{~km}$ ( this yielded a slope angle of $0.38^{\circ}$ ). Note that this is a long uniform slope as contrasted with many of the real-world slopes, which have irregularities on a smaller scale.

Figure 6 presents the control simulation of $\theta, u, w$ and $q$ at around the time of maximum upslope flow (1400 LST). As evident in Fig. 6a, a well-defined horizontal temperature gradient extending upwards to around $2 \mathrm{~km}$ is situated along the slope. This gradient has produced a horizontal velocity maximum of over $5 \mathrm{~m} \mathrm{~s}^{-1}$ with a peak vertical velocity of above $16 \mathrm{~cm}$ $\mathrm{s}^{-1}$. As found in the sea breeze simulation, a region of moisture-enriched air has been vented up by the upslope flow.

Figure 7 presents an analysis of the upslope simulation using a coarser resolution of $90 \mathrm{~km}$ (i.e., when the profilers' horizontal separation is $90 \mathrm{~km}$ ). Figure 8 presents the results when the data points (i.e., the "profiler network") from Fig. 6 used in the coarser 90 $\mathrm{km}$ analyses are shifted $45 \mathrm{~km}$. More coherence remains in these slope flow analyses as the resolution becomes coarser than was found in the sea breeze analysis. The reason is that for the specific slope case presented, the horizontal gradient of surface forcing is stretched over the entire slope of the terrain, rather than as a step function between land and water as was specified in the sea breeze case. Therefore, the response of the atmosphere for the slope case occurs over a much larger horizontal scale and is more easily resolved, even by a relatively coarse grid.

Figures 9 and 10, analogous to Figs. 4 and 5 for the sea breeze case, further illustrate the greater uniformity 

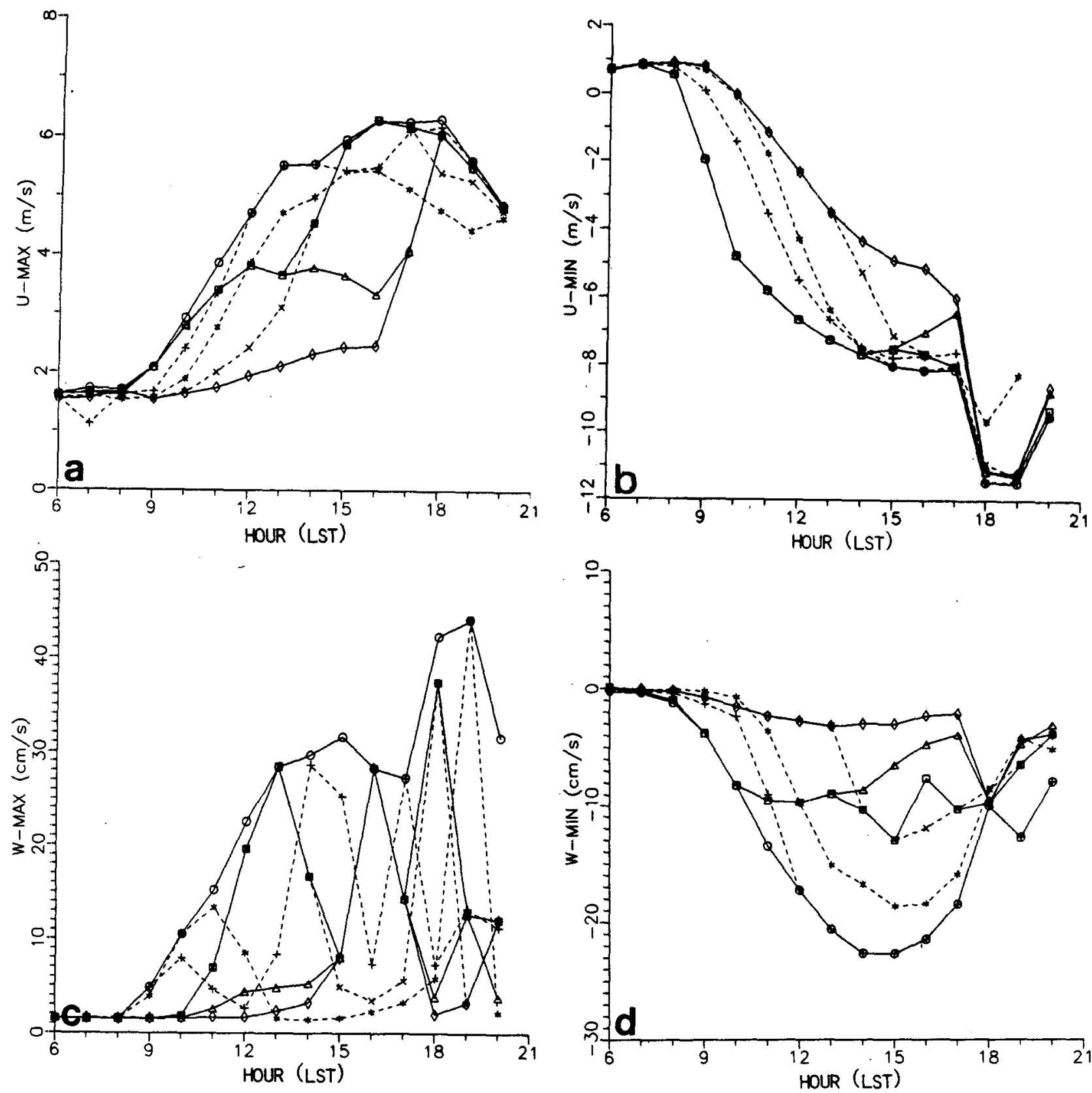

FIG. 4. Simulated maximum $u$ and $w$ (a and c) and the minimum $u$ and $w$ (b and d) within the lowest $3 \mathrm{~km}$ of the vertical cross section of the analysis domain as dependent on time $(O-6 \mathrm{~km}$ resolution; $\square-30 \mathrm{~km}$ analysis; $\triangle-60 \mathrm{~km}$ analysis; $\diamond-90 \mathrm{~km}$ analysis; +-30 $\mathrm{km}$ analysis with $15 \mathrm{~km}$ shift; $\times-60 \mathrm{~km}$ analysis with $30 \mathrm{~km}$ shift; $\star-90 \mathrm{~km}$ analysis with $45 \mathrm{~km}$ shift).

in analyses as a function of spatial resolution. Except for vertical motion, which still occurs on a small enough scale to be poorly resolved by the coarser grids, the analyses are remarkably consistent with one another over time.

\section{Additional numerical model evaluations}

In order to provide additional insight into the previous evaluations, several specific computations were carried out for the sea breeze case.

\section{a. Effective horizontal resolution of a single profiler}

It may be suggested that time-section analysis of data at a given point could minimize the need for a high horizontal resolution profiler network. For example, with a 10-minute profiler averaging time, periods of greater than 20 minutes can be sampled. If the wind speed were uniform at $5 \mathrm{~m} \mathrm{~s}^{-1}$, a distance of 6 $\mathrm{km}$, purportedly, would be represented in a 20-minute period. In the following analysis, we consider the realism of such space-time analysis for a sea breeze. We 

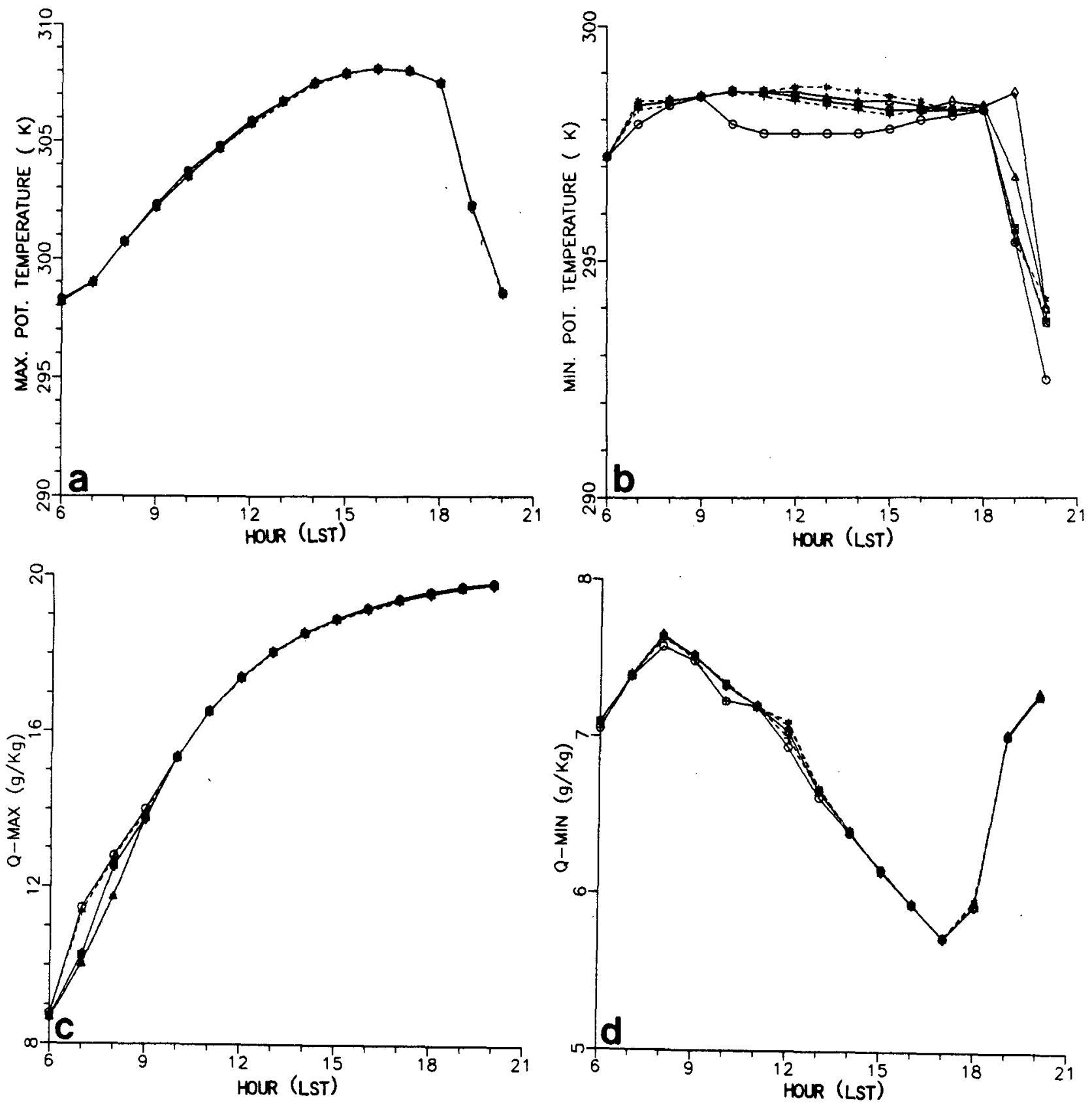

FIG. 5. Simulated maximum and minimum values of $\theta$ and $q$ along the simulated and analysis domain at a height of $5 \mathrm{~m}$ as a function of time (curves indication as in Fig. 4).

assume a single profiler is located 18 kilometers onshore.

As standard for space-time analyses, it is assumed that the measured (at $1200 \mathrm{LST}$ ) profiles of $u, v, \theta$, and $q$ at the profiler site are advected downwind while being unmodified. The onshore distance of the profiles was computed every 20 minutes based on the wind speed as a function of height measured at 1200 LST at the profiler site. The $x-z$ model profiles obtained for the sea breeze control simulation for this time interval (which were assumed to reflect the "real world" profiles) were compared against the computed single profile space-time derived "profiles." Since the sea breeze system is evolving spatially and temporally, differences between the profiles are anticipated to grow with time (or equivalently, with distance from the location of the initial profile). These features are noticeable in Fig. 11: differences in $u$ and $v$ reached values as high as $4 \mathrm{~m}$ $\mathrm{s}^{-1}$ and $1 \mathrm{~m} \mathrm{~s}^{-1}$ after 2 hours, while for $\theta$ and $q$ the peak differences were $\sim 2.3 \mathrm{~K}$ and $1.25 \mathrm{~g} \mathrm{~kg}^{-1}$. These 

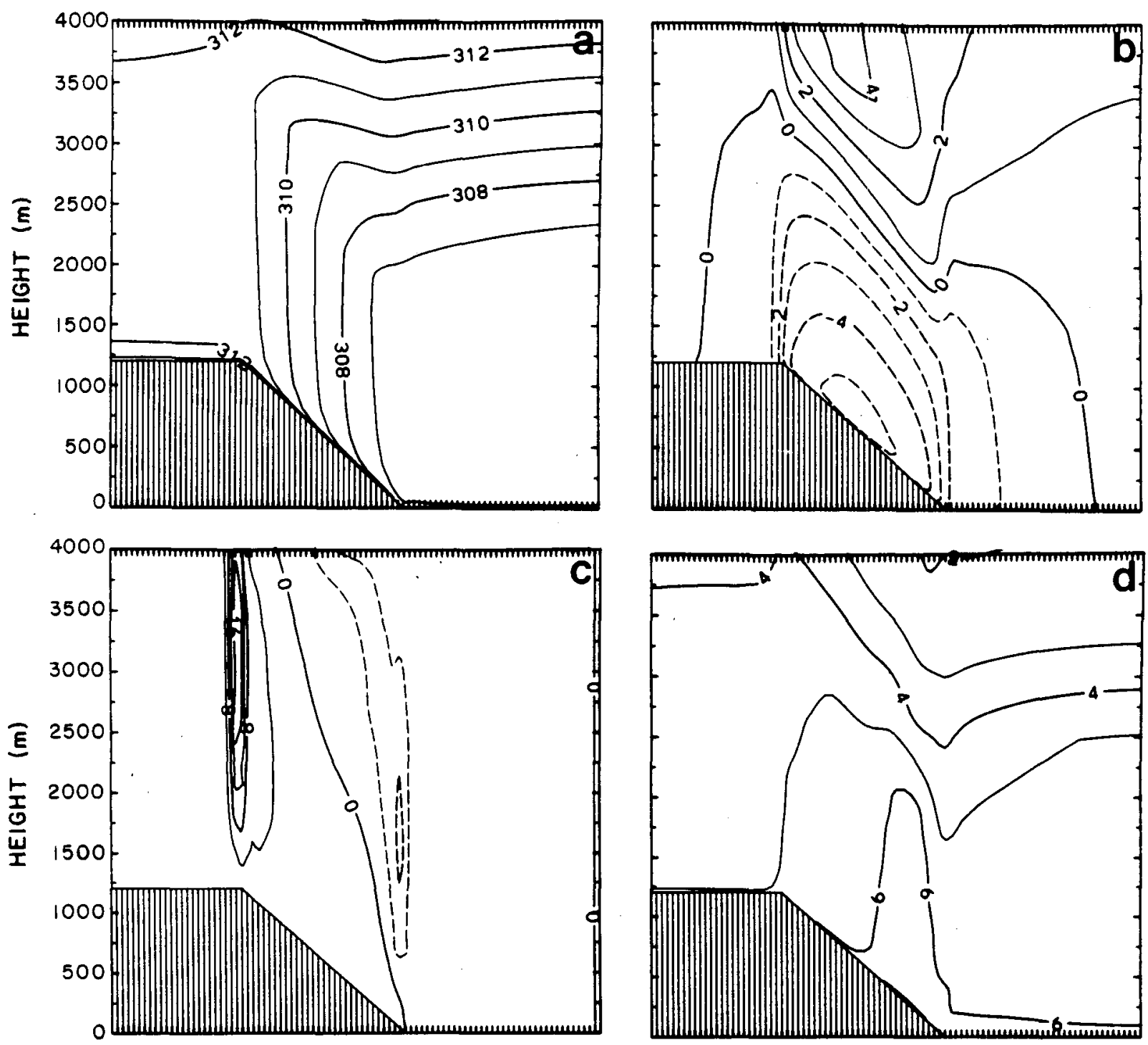

FIG. 6. The same fields and resolution presented as Fig. 1, except for the simulation of upslope flow.

differences are expected to be larger during hours of rapid temporal and spatial changes in the sea-breeze forcing, i.e., in the morning hours and late afternoon hours. Based on the specific case presented, it is suggested that a single profiler site [or even a coarse network of profilers (see Figs. 2 and 3 )] used in conjunction with space-time analyses will not be able to construct realistic analyses of sea breeze structure.

\section{b. Application of mesoscale models to improve profiler data analyses}

In order to evaluate the value of mesoscale models to improve spatial analyses obtained from profiler data the following illustrative situation was assumed: (i) the simulated fields presented in Fig. 1 (with $6 \mathrm{~km}$ hori- zontal resolution ) are the real world sea breeze fields, and (ii) at a given hour ( 1200 LST) the observed profiles of $u, v, \theta$, and $q$ are provided from the profiler network grid points presented in Fig. 2 (i.e., with a separation distance of $90 \mathrm{~km}$ ). Using these profiles, a linear interpolation of $u, v, \theta, q$ was made in order to establish the initial fields on the $6 \mathrm{~km}$ resolution model grid. Then the model was integrated for several hours and the new simulated fields were compared with the real world fields. The rationale is to determine while using coarse initial atmospheric data, whether nonlinear advective effects included in the mesoscale sea breeze model, fine scale horizontal resolution, and fine spatial resolution of the surface thermal forcing can reproduce fine scale sea breeze structure. In the specific example used, it was found that the differences in the 

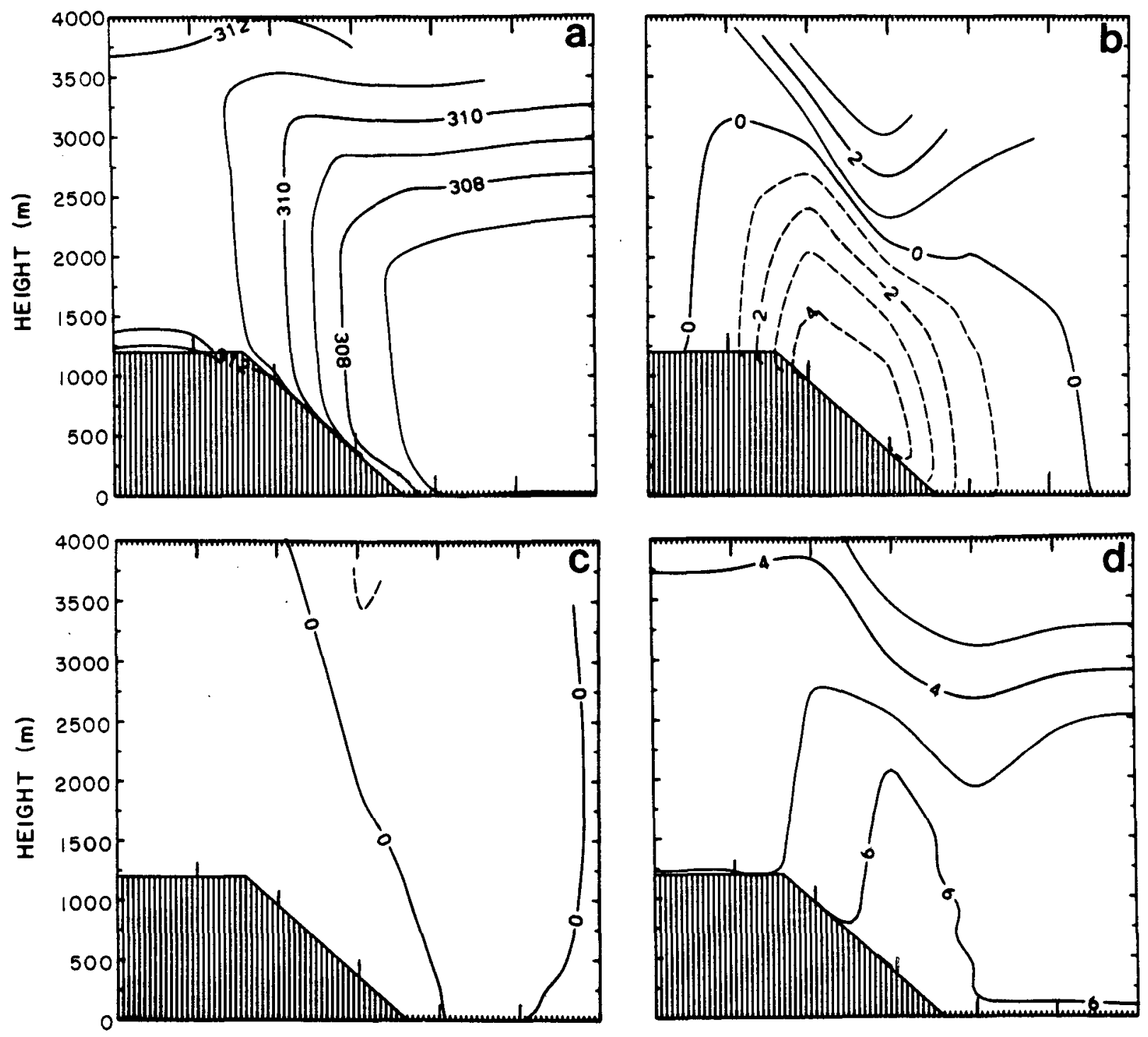

FIG. 7. The same fields and resolution presented as Fig. 2, except for the simulation of upslope flow.

$u, v, \theta$, and $q x-z$ fields obtained using the coarse observed profiles and the real world simulation were quite small following 2 hours of simulation (see Fig. 12). Following 4 hours of integration the differences between the $x-z$ fields for both cases become even smaller (not shown). This result suggests that even with coarse horizontal resolution of atmospheric structure, knowledge of the surface thermal forcing permits high spatial resolution of atmospheric features which are primarily forced by horizontal gradients in surface heating. Sensitivity simulations described in Segal et al. (1988), for example, demonstrated that either a step function type surface thermal forcing, or a gradual horizontal change of surface thermal forcing provided a similar mesoscale circulation intensity [as long as (i) the thermal difference between the cool and warm areas is the same, and (ii) the spatial gradient of thermal forcing does not extend over too large a distance]. The Segal et al. (1988) results further substantiate the conclusion that inaccuracies involved with horizontally coarse atmospheric data can be minimized using a surface-thermally forced mesoscale model as an analysis tool.

\section{Qualitative evaluations of SB and upslope flow}

The simulated cases in sections 2 and 3 provide specific examples for sea breeze and daytime upslope flow. In this section, general characteristics of these circulations are given. Also included in these evaluations are land breeze and downslope flows, although their current resolution by existing profilers is hypothetical. Table 1 provides a subjective summary of various rep- 

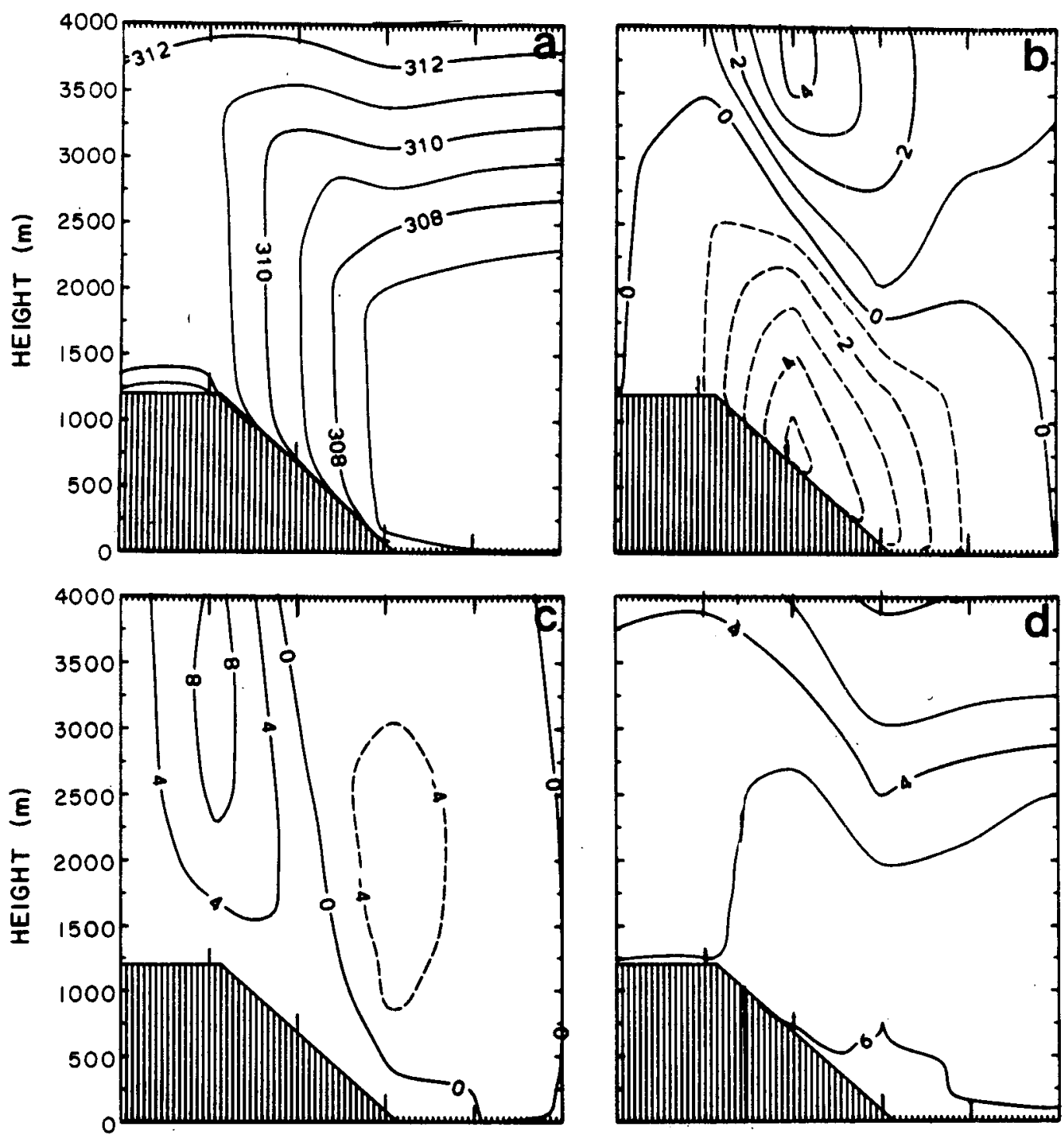

FIG. 8. The same fields and resolution presented as Fig. 3, except for the simulation of upslope flow.

resentative scales and wind speeds of relatively well documented midlatitude sea/land breeze and upslope/ downslope flows. Illustrations of the horizontal and vertical scales of these mesoscale systems are presented in more detail in Atkinson (1981) and Pielke (1984).

As evident from Table 1, the horizontal spatial scale of the mesoscale system is dependent on the magnitude and direction of the synoptic flow. Supportive synoptic flow tends to broaden the horizontal temperature gradient, while opposing synoptic flow of moderate or light speed enhances the temperature gradient, resulting in more confined mesoscale circulations.

The vertical scales of these thermally forced mesoscale systems are relatively deep during daytime, when the convective turbulence mixes heat upward to considerable heights. In contrast, during the night, partic- ularly under light winds, radiational cooling, which is most effective through a relatively shallow layer near the surface, is the dominant physical mechanism creating the horizontal temperature gradient which drives the circulation. The result is a small vertical extent. Four or more profilers must be located within the horizontal extent region of these thermally forced mesoscale systems, if an ability to resolve these features, even crudely, is to be achieved at any given time.

The vertical resolution of the profilers is dependent as to whether the mesoscale system is dominated by deep turbulent convective mixing, or by shallow radiational cooling. Since, as with the horizontal resolution, at least four sampling points per wavelength are required for an analysis of the vertical structure of the mesoscale system, $\sim 125$ meter resolution is required 

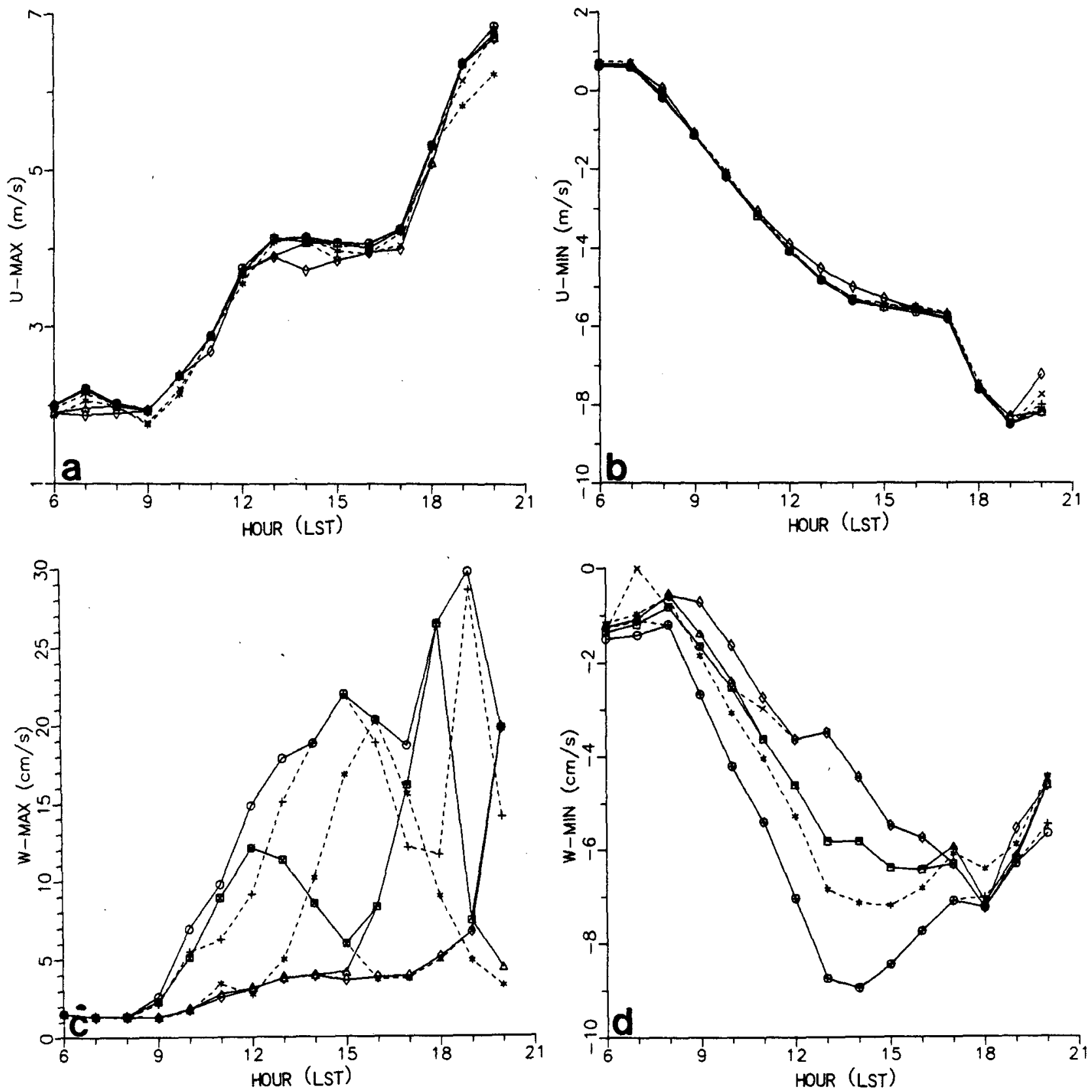

FIG. 9. The same fields and resolution presented as Fig. 4, except for the simulation of upslope flow.

for the light synoptic flow, sea breeze case. The land breeze under light synoptic flow requires at least 25 to 50 meters resolution, close to the ground.

\section{Nonclassical mesoscale circulations (NCMCs)}

Mesoscale circulations forced by nonuniform surface heating have received growing research attention in recent years. Numerical model evaluation of NCMCs indicate that their intensity can be comparable to that of a well-developed sea breeze (e.g., Ookouchi et al. 1984; Segal et al. 1986; Mahfouf et al. 1987; Yan and Anthes 1988). Only limited observational evaluations of NCMCs have been carried out. The Segal et al. (1989) observational study of NCMCs generated by irrigated area-dry land contrasts in northeast Colorado indicates at most a moderate circulation intensity. On the other hand, the results of the Cramer (1988) study suggest occasionally and mostly towards the end of the winter, noticeable NCMCs involved with snowbare ground contrasts. 

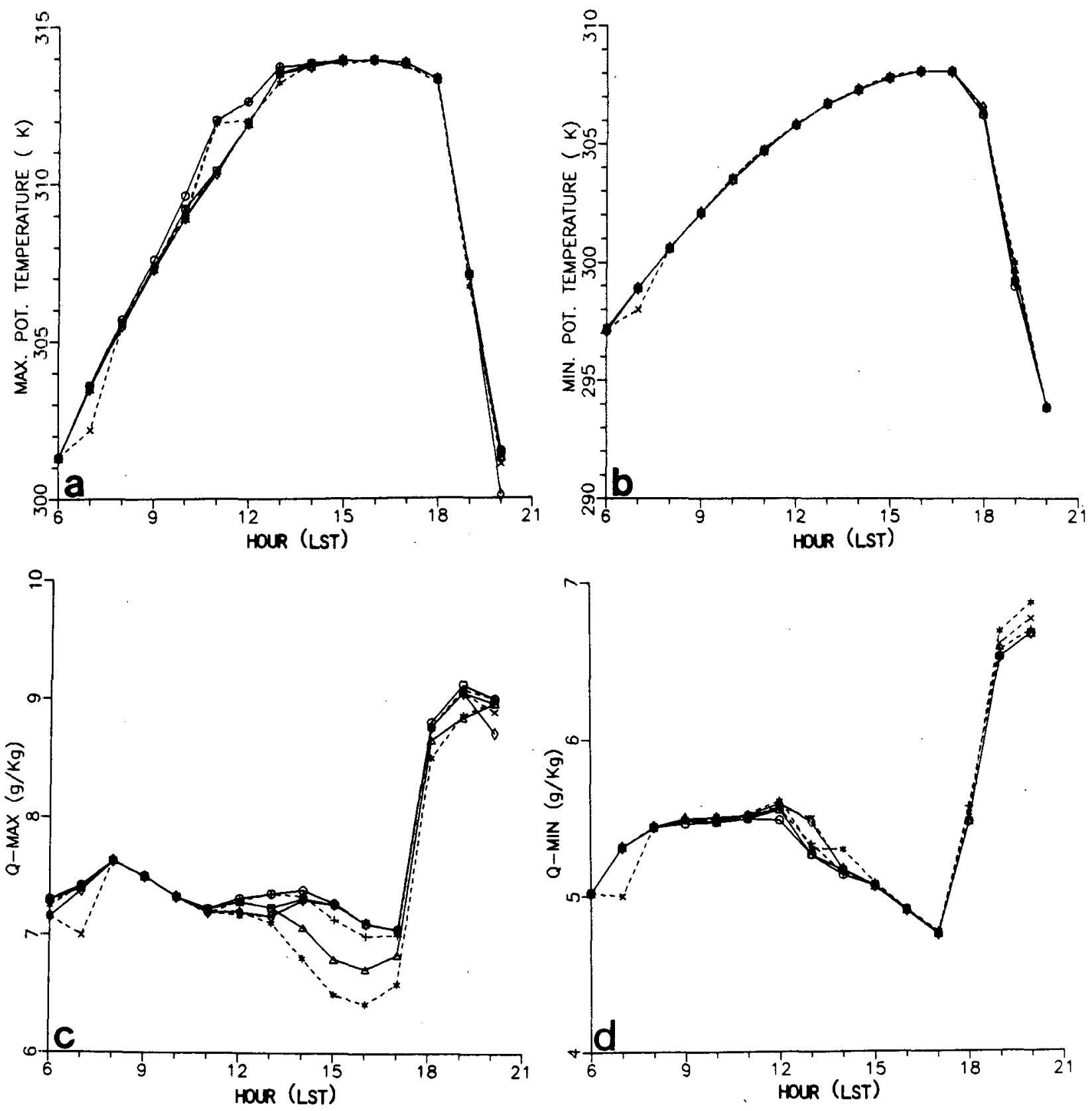

FIG. 10. The same fields and resolution presented as Fig. 5, except for the simulation of upslope flow.

NCMCs are likely to be involved in many situations with only a weak thermally induced flow. The related horizontal differentiation of sensible heat flux, however, may cause a substantial differentiation in the daytime boundary layer depth and cause a modification in the synoptic flow, e.g., Chang and Wetzel (1986). They found, in numerical model simulations, a noticeable difference in the synoptic flow while crossing from a nonirrigated to an irrigated area. Horizontal gradients in the surface sensible heat flux can also result, during the summer, in spatial variability in available convec- tive potential energy, thereby creating regions of preferred thunderstorm activity.

Two observational examples are provided in this paper that illustrate the substantial impact of variability of land use on surface temperatures within a mesoscale domain. Figure 13 provides an example of the spatial variability of a summer 2-week average temperature at $1300 \mathrm{MST}$, as obtained using GOES-derived IR surface temperatures. Figure 14 illustrates aircraft measured IR surface temperatures and their variance across southern Florida during a summer afternoon. Both of 

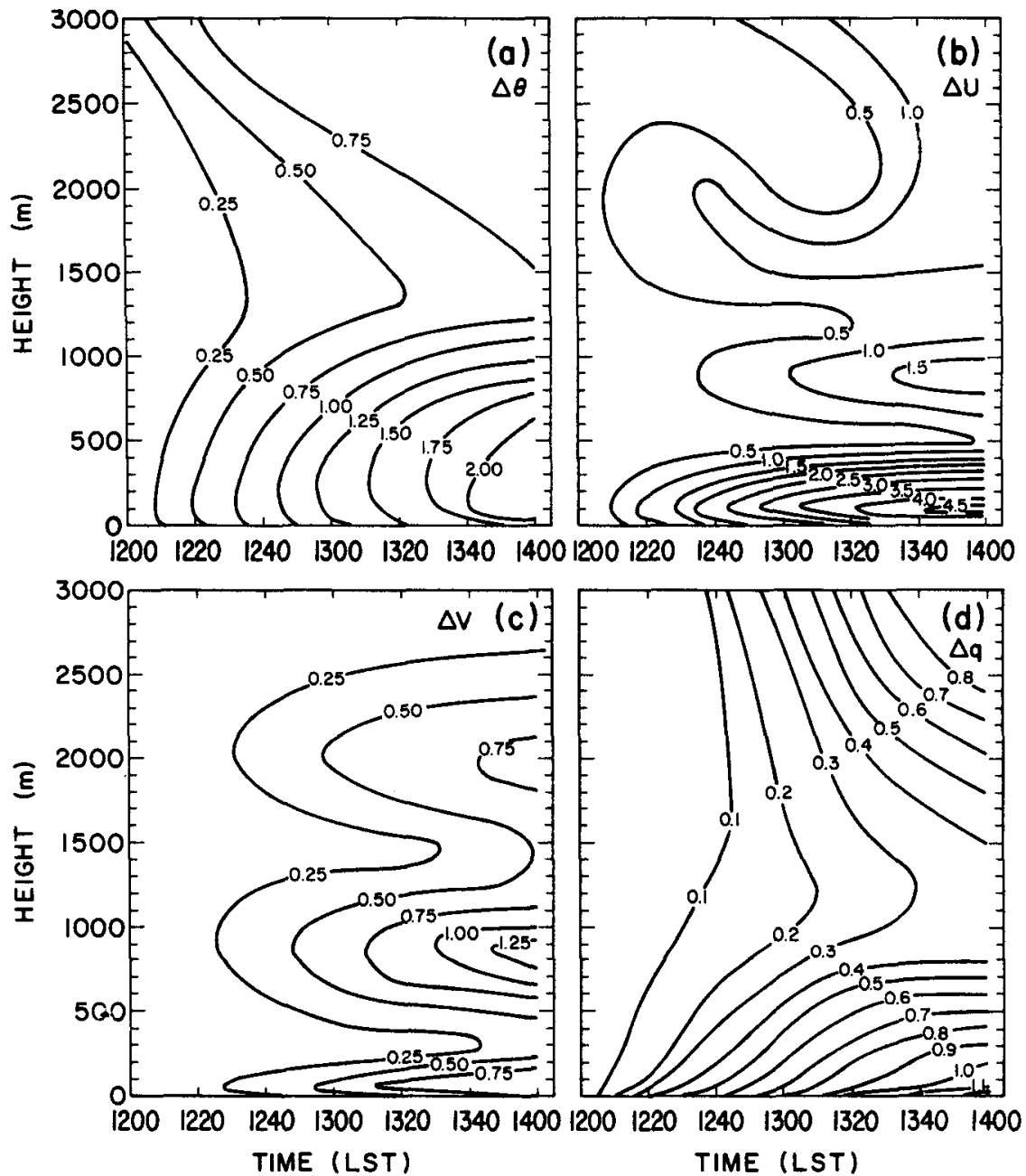

FIG. 11. Differences [absolute value; ${ }^{\circ} \mathrm{C}(\mathrm{a}), \mathrm{m} \mathrm{s}^{-1}(\mathrm{~b}, \mathrm{c})$ and $\mathrm{g} \mathrm{kg}^{-1}$ (d)] between profiles advected downwind beginning at $1200 \mathrm{LST}$ at a distance of $18 \mathrm{~km}$ onshore and the simulated profiles at the corresponding distances for the same fields presented in Fig. 1.

these examples show noticeable horizontal changes in the surface temperature within mesoscale domains. Therefore, they imply a significant spatial variability of the daytime boundary-layer depth and thus illustrate the challenge of adequately resolving the temperature forcing of thermal mesoscale systems in order to make effective use of the profiler network.

\section{The challenge of using profiler data in mesoscale models}

As described by footnote 1 , it is useful to define mesoscale as those atmospheric systems that are predominantly hydrostatic, but whose winds are significantly out of gradient-wind balance, even above the planetary boundary layer. Microscale motions are predominantly nonhydrostatic, while synoptic flow is close to gradient balance above the boundary layer and turns towards low pressure within the boundary layer as a result of an average large-scale frictional retardation.

Formally, using these definitions the wind field can be decomposed into

$$
\begin{aligned}
u(x, y, z, t)= & u_{0}(x, y, z, t) \\
& \quad+u^{\prime}(x, y, z, t)+u^{\prime \prime}(x, y, z, t) \\
v(x, y, z, t)= & v_{0}(x, y, z, t) \\
& \quad+v^{\prime}(x, y, z, t)+v^{\prime \prime}(x, y, z, t) \\
w(x, y, z, t)= & w_{0}(x, y, z, t) \\
& +w^{\prime}(x, y, z, t)+w^{\prime \prime}(x, y, z, t) \quad(1)
\end{aligned}
$$

where the components with the subscripts ( ) $)_{0}$ refer to synoptic scale flow and ()$^{\prime}$ and ()$^{\prime \prime}$ quantities refer to mesoscale and microscale motions, respectively. Pielke et al. (1987) presents a recent discussion 

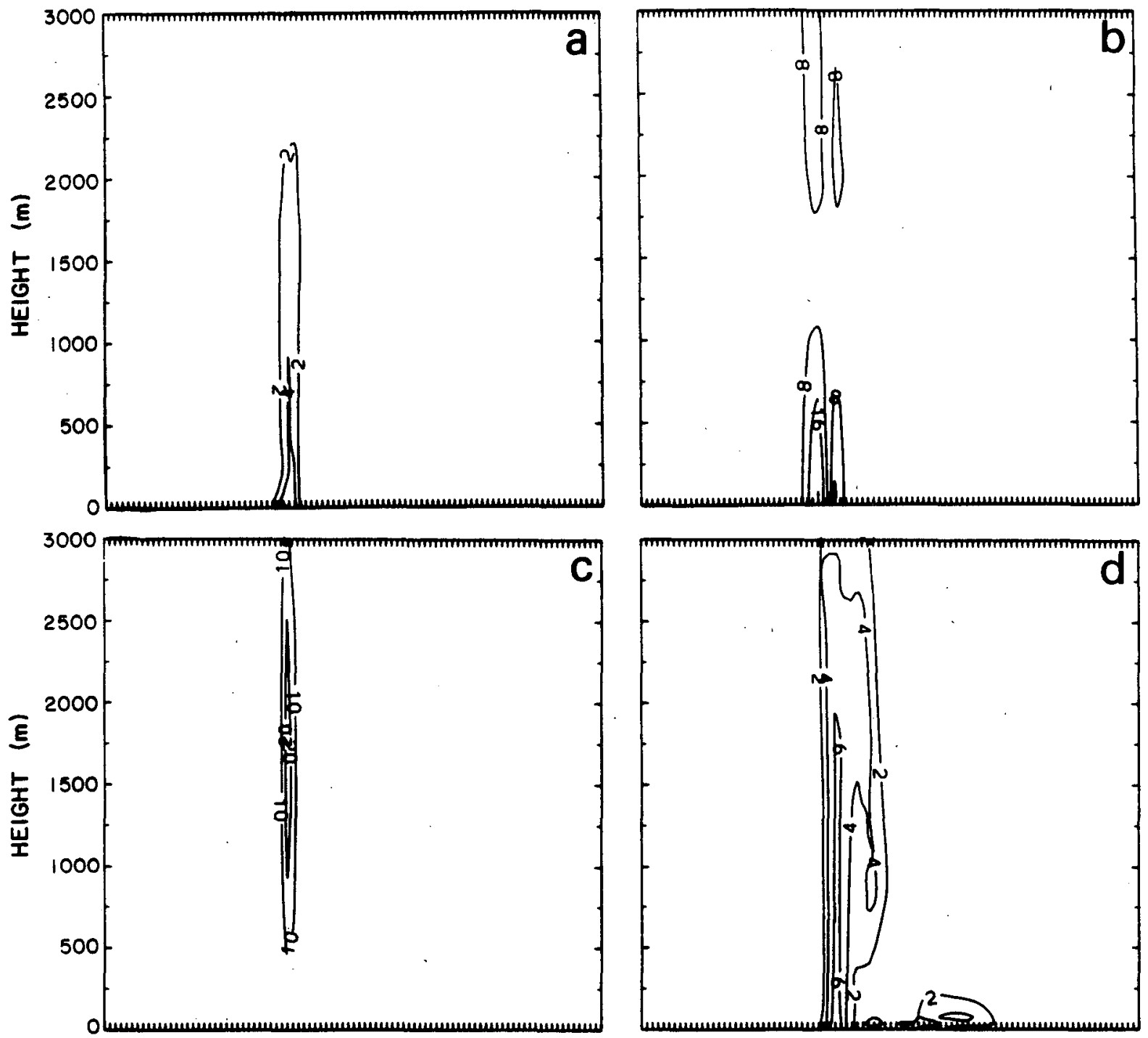

FIG. 12. The differences at 1400 LST between the sea breeze control simulation fields and the corresponding simulated fields based on an initialization interpolated from the 1200 LST profilers with a horizontal resolution of $90 \mathrm{~km}$ (as obtained in the control simulation) and integrated forward for two hours. (a) $\Delta \theta \times 10(K)$, (b) $\Delta u \times 10\left(\mathrm{~m} \mathrm{~s}^{-1}\right)$, (c) $\Delta w$ (cm s${ }^{-1}$ ), and (d) $\Delta q \times 10$ $\left(\mathrm{g} \mathrm{kg}^{-1}\right)$.

of the rationale for this categorization of the scales of flow. Similarly, temperature and specific humidity can be decomposed into

$$
\begin{aligned}
T(x, y, z, t)= & T_{0}(x, y, z, t) \\
& \quad+T^{\prime}(x, y, z, t)+T^{\prime \prime}(x, y, z, t) \\
q(x, y, z, t)= & q_{0}(x, y, z, t) \\
& +q^{\prime}(x, y, z, t)+q^{\prime \prime}(x, y, z, t) .
\end{aligned}
$$

An important simplification on the synoptic scale is that since the winds on this scale are defined to be close to gradient balance above the boundary layer, knowledge of the synoptic temperature field, $T_{0}(x, y, z, t)$, at a given time provides an accurate characterization of the synoptic velocity field above the boundary layer through the thickness and thermal wind relation. The hydrostatic relation permits the temperature field to be used to diagnostically calculate the pressure field and, therefore, the balanced velocities. Because the winds are close to gradient balance, the horizontal winds are primarily rotational (i.e., $\mathbf{V}_{H_{0}} \approx \mathbf{k} \times \nabla \psi$ ). Synoptic vertical motion, $w_{0}(x, y, z, t)$, is required in order to retain this direct equivalence between the instantaneous temperature and velocity fields. Quasigeostrophic theory and the resultant "omega-equation" (Haltiner 1971) provide a mathematical description of this synoptic relationship.

On the mesoscale, since the wind is not, in general, close to gradient balance even above the boundary 
TABLE 1. Typical range of some characteristics of midsummer and subtropical/low midlatitude sea/land breeze and thermally induced upslope/downslope flow circulations.

\begin{tabular}{|c|c|c|c|}
\hline & Horizontal extent (km) & $\begin{array}{l}\text { Vertical extent } \\
(\mathbf{k m})\end{array}$ & $\begin{array}{l}\text { Wind speed } \\
\left(\mathrm{m} \mathrm{s}^{-1}\right)\end{array}$ \\
\hline $\begin{array}{l}\text { Light synoptic flow } \\
\text { Sea breeze } \\
\text { Land breeze } \\
\text { Upslope flow } \\
\text { Downslope flow }\end{array}$ & $\begin{array}{l}\sim 50 \mathrm{~km} \text { (onshore) } \\
\sim 10-20 \mathrm{~km} \\
\text { Slope length and extensions } \\
\text { Slope length and extensions }\end{array}$ & $\begin{array}{l}0.5-1 \\
0.1-0.2 \\
1 \\
0.1-0.2\end{array}$ & $\begin{array}{l}4-8 \\
2-3 \\
4-8 \\
3-6\end{array}$ \\
\hline $\begin{array}{l}\text { Supportive synoptic flow } \sim 3 \mathrm{~m} \mathrm{~s}^{-1} \\
\text { Sea breeze } \\
\text { Land breeze } \\
\text { Upslope } \\
\text { Downslope }\end{array}$ & $\begin{array}{l}50-150 \mathrm{~km} \\
\sim 10 \mathrm{~km} \text { (onshore) } \\
\text { Somewhat larger than slope length } \\
\text { Somewhat larger than slope length }\end{array}$ & $\begin{array}{l}0.5-1 \\
0.1 \\
1 \\
0.1\end{array}$ & $\begin{array}{l}6-9 \\
3-4 \\
6-9 \\
5-10\end{array}$ \\
\hline $\begin{array}{l}\text { Opposing synoptic flow } \sim 3 \mathrm{~m} \mathrm{~s}^{-1} \\
\text { Sea breeze } \\
\text { Land breeze } \\
\text { Upslope } \\
\text { Downslope }\end{array}$ & $\begin{array}{l}5-20 \mathrm{~km} \\
\sim 0 \mathrm{~km} \\
\text { Portion of slope } \\
\text { Portion of slope }\end{array}$ & $\begin{array}{l}0.2-0.4 \\
0.05 \\
0.2-0.4 \\
0.1\end{array}$ & $\begin{array}{l}1-3 \\
1-2 \\
2-4 \\
2-4\end{array}$ \\
\hline
\end{tabular}

layer, an explicit relation between the instantaneous temperature and velocity fields does not exist. Since the mesoscale is hydrostatic, however, a diagnostic relation between temperature and pressure remains, even though the near balance between the pressure and velocity fields does not. The mesoscale horizontal winds $u^{\prime}(x, y, z, t)$ and $v^{\prime}(x, y, z, t)$, in contrast to the synoptic horizontal flow, have a substantial divergent component of the wind (i.e., $\mathbf{V}_{H}^{\prime}=\mathbf{k} \times \nabla \psi^{\prime}+\nabla \chi^{\prime}$; where $\psi^{\prime}$ is the streamfunction and $\chi^{\prime}$ is the velocity potential). Thus, to obtain the mesoscale horizontal flow, both the instantaneous value and the time evolution of the mesoscale temperature field must be monitored by a profiler network. Table 2 provides a sum- mary of several of the distinguishing characteristics of the three separate scales of motion.

To further illustrate the challenge of using mesoscale profiler measurements of temperature to obtain the horizontal velocity field, the east-west mesoscale equation of motion can be written from Pielke (1984, p. 363 ) as

$$
\frac{\partial u^{\prime}}{\partial t}=\frac{\partial}{\partial x}\left(\frac{u^{\prime 2}}{2}\right)-\alpha_{0} \frac{\partial p^{\prime}}{\partial x}+R
$$

where $R$ represents the remaining terms in the equation. Equation (3) can be integrated between profiler locations, yielding

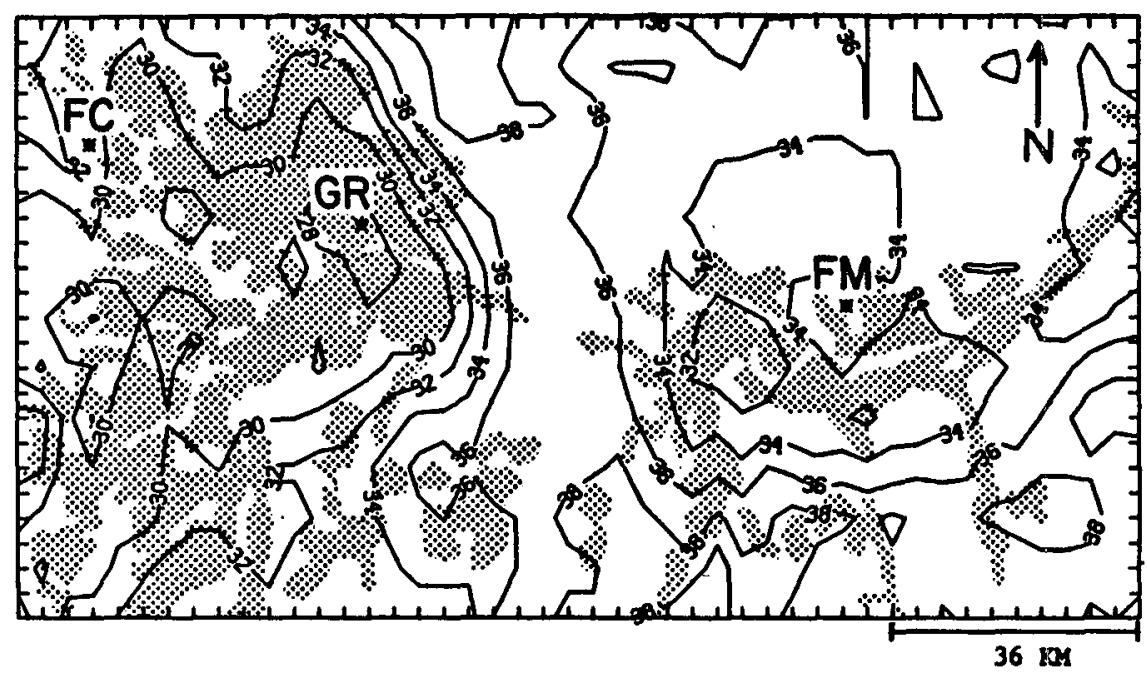

FIG. 13. Composite of GOES derived surface temperature for northeast Colorado for the period 1 August 1986-15 August 1986 at 1300 LST. Irrigated areas are shaded; FC-Fort Collins, GRGreeley, FM-Fort Morgan. (From Segal et al. 1988a.) 

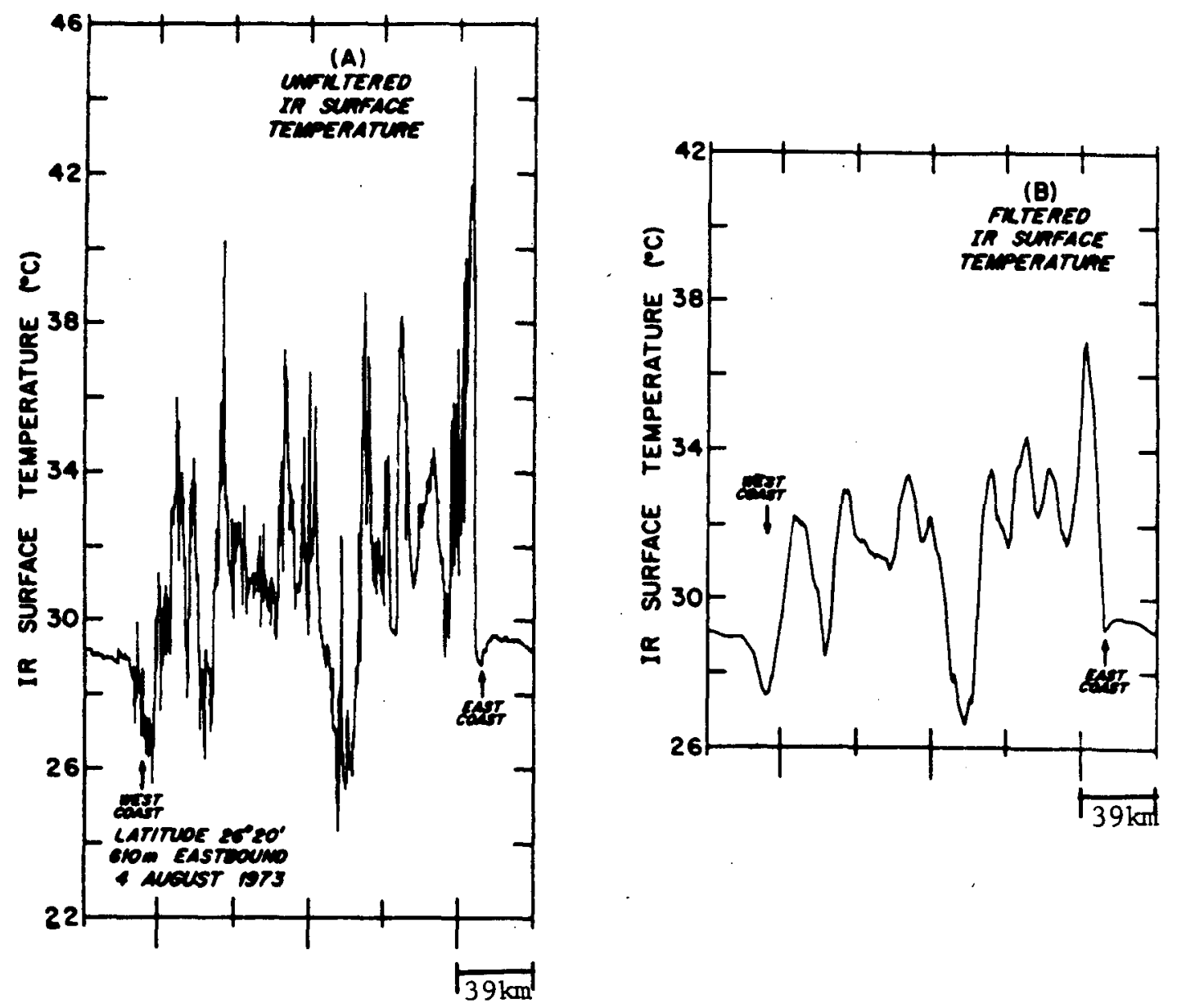

FIG. 14. Infrared surface temperature for the period 1051-1136 ESD from an aircraft cross section for 4 August 1973: (a) unfiltered data, (b) $11 \mathrm{~km}$ averaged data. (From Pielke and Cotton 1977.)

$\frac{\partial \hat{u}}{\partial t}=\frac{u_{E}^{\prime 2}-u_{W}^{\prime 2}}{2 D_{x}}-\alpha_{0} \frac{p_{E}^{\prime}-p_{W}^{\prime}}{D_{x}}+\int_{x}^{x+D_{x}} R d \tilde{x} / D_{x}$

where the subscripts $E$ and $W$ represent the values of the east-west velocity and pressure at two adjacent profilers where separation is denoted by $D_{x}$. The average acceleration across the separation distance is rep- resented by $\partial \hat{u} / \partial t$.

Table 3 presents values of the first two terms on the right of Eq. (4) that would cause an average acceleration of $1 \mathrm{~m} \mathrm{~s}^{-1} / \mathrm{h}$. We can interpret this value as a relative error in the profiler measurements above which unacceptable results would occur in a model initialization or in an analysis such as applied in section $4 b$.

TABLE 2. Summary justification for the three scales of atmospheric motion.

\begin{tabular}{|c|c|c|}
\hline Synoptic & Mesoscale & Microscale \\
\hline Hydrostatic & Hydrostatic & Nonhydrostatic \\
\hline $\mathbf{V}_{H_{0}} \approx \mathbf{k} \times \nabla \psi_{0}$ & $\mathbf{V}_{H}^{\prime}=\mathbf{k} \times \nabla \psi^{\prime}+\nabla x^{\prime}$ & $\mathbf{V}_{H}^{\prime \prime}=\mathbf{k} \times \nabla \psi^{\prime \prime}+\nabla x^{\prime \prime}$ \\
\hline$\omega_{0}$ from quasi-geostrophic theory & $\omega^{\prime}$ from the anelastic continuity equation & $\omega^{\prime \prime}$ from the anelastic continuity equation \\
\hline $\begin{array}{l}\text { Instantaneous temperature field } \\
\text { provides the velocity field } \\
{\left[T_{0}(x, y, z, \tilde{l}) \Rightarrow \mathrm{V}_{H_{0}}(x, y, z, t)\right]}\end{array}$ & $\begin{array}{l}\text { Instantaneous and time evolution of } \\
\text { temperature field provides the velocity } \\
\text { field }\left[\int_{t_{0}}^{\bar{t}} T^{\prime}(x, y, z, t) d t \Rightarrow \mathbf{V}_{H}^{t}(x, y, z, t)\right]\end{array}$ & $\begin{array}{l}\text { Temperature field by itself is insufficient } \\
\text { to characterize wind field }\end{array}$ \\
\hline Rossby number much less than unity & Rossby number on the order of unity & $\begin{array}{l}\text { Rossby number on the order of unity or } \\
\text { greater }\end{array}$ \\
\hline
\end{tabular}


TABLE 3. The values needed in Eq. (4) to generate an acceleration at level $z$ of $1 \mathrm{~m} \mathrm{~s}^{-1} \mathrm{~h}^{-1}$. A value of $\alpha_{0}=1 \mathrm{~m}^{3} \mathrm{~kg}^{-1}$ was used in computing the pressure gradient force. From Pielke (1984, p. 364).

\begin{tabular}{|c|c|c|c|c|c|c|}
\hline \multirow{2}{*}{$\begin{array}{r}D_{x} \\
(\mathbf{k m})\end{array}$} & \multirow{2}{*}{$\begin{array}{c}\left(u_{E}^{\prime 2}-u_{W}^{\prime 2}\right) / 2 \\
\left(\mathrm{~m}^{2} \mathrm{~s}^{-2}\right)\end{array}$} & \multirow{2}{*}{$\begin{array}{c}\alpha_{0}\left(p_{E}^{\prime}-p_{W}^{\prime}\right) \\
\left(\mathrm{m}^{2} \mathrm{~s}^{-2}\right)\end{array}$} & \multicolumn{3}{|c|}{$\begin{array}{l}\Delta u^{\prime}\left(\mathrm{m} \mathrm{s}^{-1}\right) \text { for } \\
\hat{u}_{W}\left(\mathrm{~m} \mathrm{~s}^{-1}\right) \text { of }\end{array}$} & \multirow{2}{*}{$\begin{array}{c}p_{E}^{\prime}-p_{W}^{\prime} \\
(\mathrm{mb})\end{array}$} \\
\hline & & & 0 & 5 & 10 & \\
\hline 1000 & 278.0 & 278.0 & 23.6 & 19.1 & 15.6 & 2.78 \\
\hline 100 & 28.0 & 28.0 & 7.6 & 4.0 & 2.5 & 0.28 \\
\hline 10 & 2.8 & 2.8 & 2.4 & 0.5 & 0.3 & 0.03 \\
\hline
\end{tabular}

When frictional deceleration is considered in (4) (e.g., when the flow is within the planetary boundary layer), the erroneous acceleration will not result in an indefinite increase in velocity. However, the fictitious addition of kinetic energy associated with this acceleration will still result in errors in a model simulation, although the effect will be damped. In any case, the maximum acceptable value for an error in $\partial \hat{u} / \partial t$ must be evaluated for each specific situation. In this discussion, $\partial \hat{u} / \partial t=1 \mathrm{~m} \mathrm{~s}^{-1} \mathrm{~h}^{-1}$ is arbitrarily selected. One can choose a higher value if frictional effects are significant. Equation (4) evaluated at $E$ and $\bar{W}$ for a synoptic scale spacing (i.e., $D_{x}=1000 \mathrm{~km}$ ) requires relatively large differences in pressure or velocity in order to generate an acceleration of $1 \mathrm{~m} \mathrm{~s}^{-1} \mathrm{~h}^{-1}$. In terms of temperature, a layer-averaged temperature gradient error of about $2.31^{\circ} \mathrm{C}$ over a depth of $2 \mathrm{~km}$ would produce a pressure gradient error of $2.78 \mathrm{mb}$. Measurement accuracy from the profilers must be better than this error to achieve realistic direct monitoring of the synoptic pressure gradient field. For a mesoscale sized area (i.e., $100 \mathrm{~km}$ ), however, the limits are much more restrictive. Observational accuracy of $0.28 \mathrm{mb}$ for $p_{E^{\prime}}$ $-p_{W^{\prime}}$ is required. (This corresponds to a layer-averaged temperature gradient of only $0.24^{\circ} \mathrm{C}$ !) For the same resolution, with winds from one profiler of 0,5 , and $10 \mathrm{~m} \mathrm{~s}^{-1}$, an error in the adjacent $10 \mathrm{~km}$ separated wind profiler of $2.4,0.5$, and $0.3 \mathrm{~m} \mathrm{~s}^{-1}$, respectively, would result in the same erroneous acceleration. The toleration of a larger erroneous acceleration in $\partial \hat{u} / \partial t$, such as might occur in atmospheric systems with actual large horizontal accelerations, will permit a somewhat less stringent observational requirement.

\section{Conclusions}

For a propagating mesoscale system whose intensity and structure is not changing with time, relatively coarse horizontal profiler resolution is sufficient to resolve the feature since the circulation would pass by the profiler sites quickly enough to construct a threedimensional analysis. This is generally not true for a thermally forced mesoscale system. For mesoscale systems which are generated by surface inhomogeneities in surface heating (e.g., land-sea contrasts, nonuniform soil wetness, etc.), such propagation is often slow. Therefore, if thermally surface-forced systems are to be directly resolved by a profiler network, a necessary condition is that their spacing be close enough to adequately resolve the motion field of the mesoscale system. As concluded from the analyses in this paper, higher resolution is required to monitor horizontal winds than temperature, since the horizontal wind field is proportional to the horizontal gradient of temperature. Similarly, even higher resolution of vertical velocity is required since ascent and descent are proportional to the horizontal gradient of the horizontal velocity.

The use of mesoscale numerical models as analysis tools, however, offers the opportunity to obtain finescale horizontal resolution with only relatively coarse atmospheric data. Such fine scale resolution is obtained because the surface thermal forcing can be resolved with high spatial accuracy and, through nonlinear advection and the pressure gradient force in the numerical model, fine-scale atmospheric structure can be produced.

Finally, there are stringent data initialization requirements that would result if one attempted to directly insert mesoscale resolution profiler-derived temperature or wind data into a model. Even if $10 \mathrm{~km}$ horizontal resolution were obtained with a profiler network, if relative errors in the temperature measurements were only $0.24^{\circ} \mathrm{C}$ through a depth of $2 \mathrm{~km}$ or so, a fictitious $1 \mathrm{~m} \mathrm{~s}^{-1} \mathrm{~h}^{-1}$ acceleration would result. For the same resolution, for winds from one profiler of 0,5 , and $10 \mathrm{~m} \mathrm{~s}^{-1}$, an error in the adjacent profiler of $2.4,0.5$, and $0.3 \mathrm{~m} \mathrm{~s}^{-1}$, respectively, would result in the same erroneous acceleration.

Acknowledgments. Research support to prepare this paper was provided by ARO Grant No. DAAL03-86K-0175 and by NSF Grant ATM-8616662. CRAY computer resources were provided by NCAR. Ray Arritt is thanked for his comments in the preparation of the paper. Comments by the reviewers were useful in improvement of the manuscript. The authors would also like to thank Doug Lilly and Bill Shenk for their comments during the oral presentation of this work. The typing and editing of this paper were very competently handled by Dallas McDonald.

\section{REFERENCES}

Atkinson, B. W., 1981: Mesoscale Atmospheric Circulations. Academic Press, $495 \mathrm{pp}$.

Chang, J.-T., and P. J. Wetzel, 1986: Role of evapotranspiration in a pre-storm environment: effects of spatial variations of soil moisture and vegetation. Proc. International Conf. Monsoon and Mesoscale Meteorology, Taipei, Taiwan, Amer. Meteor. Soc., $148-153$.

Cramer, J., 1988: Observations of the boundary layer over snow covered ground. M.S. thesis, Dept. of Atmospheric Sci., Colorado State University, Fort Collins, CO, $112 \mathrm{pp}$.

Haltiner, G. J., 1971: Numerical Weather Prediction. Wiley, 317 pp. Kuo, Y.-H., E. G. Donall and M. Shapiro, 1987: Feasibility of short 
range numerical weather prediction using observations from a network of profilers. Mon. Wea. Rev., 115, 2402-2427.

Mahfouf, J. F., E. Richard and P. Mascart, 1987: The influence of soil and vegetation on the development of mesoscale circulations. J. Climate Appl. Meteor., 26, 1483-1495.

Mahrer, Y., and R. A. Pielke, 1977: A numerical study of the airflow over irregular terrain. Contrib. Atmos. Phys., 50, 98-113.

Ookouchi, Y., M. Segal, R. C. Kessler and R. A. Pielke, 1984: Evaluation of soil moisture effects on the generation and modification of mesoscale circulations. Mon. Wea. Rev., 112, 2281-2292.

Pielke, R. A., 1974: A three-dimensional numerical model of the sea breezes over south Florida. Mon. Wea. Rev., 102, 115-139.

__ 1984: Mesoscale Meteorological Modeling. Academic Press, $612 \mathrm{pp}$.

- and W. R. Cotton, 1977: A mesoscale analysis over south Florida for a high rainfall event. Mon. Wea. Rev., 105, 343-362.

- and M. Segal, 1986: Mesoscale circulations forced by differential terrain heating. Mesoscale Meteorology and Forecasting, P. Ray, Ed., Amer. Meteor Soc., 516-548.

- R. W. Arritt, M. Segal, M. D. Moran and R. T. McNider,
1987: Mesoscale numerical modeling of pollutant transport in complex terrain. Bound.-Layer Meteor., 41, 59-74.

Segal, M., R. A. Pielke and Y. Mahrer, 1984: Evaluation of surface sensible heat flux effects on the generation and modification of mesoscale circulations. Proceedings of the Nowcasting II Symposium, Norrkoping, Sweden, 263-269.

_ , J. F. W. Purdom, R. A. Piel.ke, Y. Mahrer and J. L. Song, 1986: Evaluation of cloud shading effects on the generation and modification of mesoscale circulations. Mon. Wea. Rev., 114, $1201-1212$

_- R. Avissar, M. C. McCumber and R. A. Pielke, 1988: Evaluation of vegetation effects on the generation and modification of mesoscale circulations. J. Atmos. Sci., 45, 2268-2292.

- -, W. E. Schreiber, G. Kallos, J. R. Garratt, A. Rodi, J. Weaver and R. A. Pielke, 1989: The impact of crop areas in northeast Colorado on mid-summer mesoscale thermal circulations. Mon. Wea. Rev. 117, 801-825.

Yan, H., and R. A. Anthes, 1988: The effect of variations in surface moisture on mesoscale circulations. Mon. Wea. Rev., 116, 192208 